\title{
Obituary (Prof. Dr. Konrad Haider)
}

\section{July 1928-3 September 2015}

\author{
Andreas Schaeffer ${ }^{1}$
}

Published online: 6 October 2015

(C) Springer-Verlag Berlin Heidelberg 2015

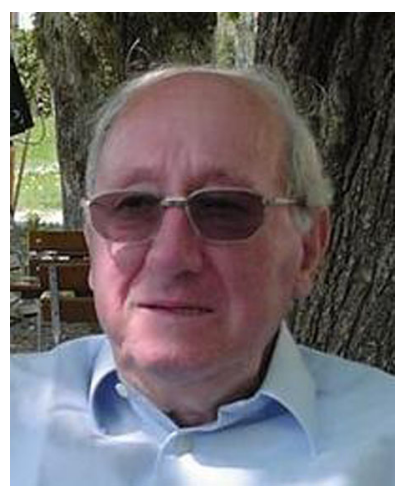

Konrad Haider, one of the main pioneers in soil humus research, died on Sep. 03, 2015 in the age of 87. He, independently but also often in cooperation with the most influential soil scientists of the last century, significantly contributed to our knowledge of key processes in organic matter formation, the essential component of our soil resources. In particular, he investigated the role of fungi in structuring and forming humic matter, studied the contribution of abiotic soil catalysts in these processes, and elucidated the interactions of soil compo-

nents in binding and degrading xenobiotic chemicals, e.g., pesticides. Prof. Haider was very successful in the application of innovative tracer experiments with isotope-labelled xenobiotics and natural litter to study their fate in soil. He was one of the first to address the issue of non-extractable residues of xenobiotics using, at that time, innovative spectroscopic methods. He published more than 120 scientific papers between 1963 and 2005. As a matter of course, part of his conclusions nowadays has been set into other perspectives since new analytical characterization methods have become available; one example is the still ongoing discussion on the polymeric nature of humic material. Because of his achievements, he was elected as honorary member of the International Humic Substances Society.

His experiments laid the cornerstone of the current understanding of soil organic matter formation, and his findings and conclusions inspired generations of younger researchers to direct and advance their study aims. Besides his scientific input, also his stringent, sometimes, especially in younger age, provocative statements and his overall humorous, supportive, and friendly manner influenced the careers of many scientists including that of myself.

Andreas Schaeffer

andreas.schaeffer@bio5.rwth-aachen.de

Institute for Environmental Research, RWTH Aachen University, 52074 Aachen, Germany 